\title{
Feedback imediato em ambientes informatizados através de vídeos na disciplina de matemática
}

\section{Immediate feedback in computerized environments through videos in mathematics discipline}

\author{
JORGE NAZARENO BATISTA MELO \\ Colégio Militar de Porto Alegre
}

ALBERTO BASTOS DO CANTO FILHO

Universidade Federal do Rio Grande do Sul

JOSÉ VALDENI DE LIMA

Universidade Federal do Rio Grande do Sul

\begin{abstract}
Resumo: No contexto escolar, a avaliação permeia todo o processo ensino-aprendizagem. Entretanto, muitas vezes a avaliação tem simplesmente o caráter comparativo e classificatório, sem atender às necessidades individuais dos alunos e sem oferecer o devido retorno. Assim, 0 feedback adequado pode ser um retorno que conscientiza os alunos sobre suas habilidades, suas competências, seus conhecimentos e como os mesmos são obtidos. Este trabalho discute e apresenta os resultados de um experimento pedagógico, realizado no Ensino Médio de uma escola pública, em que é desenvolvido retorno imediato através de vídeo-feedback de atividades desenvolvidas no âmbito da disciplina de matemática, disponibilizado em ambiente informatizado. O objetivo deste vídeo-feedback é promover, de forma personalizada, melhoria do desempenho de cada aluno. Os resultados obtidos através do experimento mostraram, com base em método estatístico, evidências suficientes que indicam uma melhoria no desempenho dos alunos em matemática que utilizaram os vídeos-feedback durante a atividade de avaliação.
\end{abstract}

Palavras-chave: Feedback. Vídeos. Matemática. Avaliação.

Abstract: In the school context, evaluation permeates the entire teaching-learning process. However, the evaluation is often simply comparative and classificatory, without attending to the individual needs of the students and without offering the necessary return. Thus, appropriate feedback can be a return that provides important information about students' competencies, what they know, what they do, and how they do it. This work discusses and presents the results of a pedagogic experiment, carried out in the High School of a public school, in which an immediate feedback process is developed in the mathematics discipline, made available in a computerized environment, through videos-feedback, whose objective is to promote in a performance of students. The research showed, through statistical test, sufficient evidence that indicated the promotion of student performance in mathematics, after the use of videosfeedback, inserted in evaluation in computerized environment.

Keywords: Feedback. Videos. Math. Evaluation.

MELO, Jorge Nazareno Batista Melo; CANTO FILHO, Alberto Bastos do; DE LIMA, José Valdeni; Feedback imediato em ambientes informatizados através de vídeos na disciplina de matemática. Informática na Educação: teoria \& prática, Porto Alegre, v. 21, n. 2, p. 31-44, mai./ago. 2018. 


\section{Introdução e Motivação}

No contexto educacional, ao se falar em avaliação, todos as atenções se voltam imediatamente para a figura do aluno, ou de forma mais específica, aos resultados apresentados por este aluno quando submetido a um desafio.

Mas, esta é uma visão simplista de um processo bem mais complexo, que é constituído por variáveis diversas que se entrelaçam e se dialogam, contribuindo para o dinâmico processo ensino-aprendizagem. Neste artigo, os autores não separam os esforços de ensino dos de aprendizagem, eles preferem focar como sendo um único processo chamado de "processo ensinoaprendizagem". A razão é o trocadilho perfeito da educação: "quando eu ensino eu aprendo e quando eu aprendo eu ensino".

Desta forma, a avaliação escolar é também atividade indissociável do processo ensinoaprendizagem e deve estar presente em todas as outras atividades inerentes, por exemplo, a capacidade de análise das relações de interdependência entre os professores, entre alunos e entre o professor e seus alunos.

Segundo Luckesi (2008, p. 33), "a avaliação é um julgamento de valor sobre manifestações relevantes da realidade, tendo em vista uma tomada de decisão". Ou seja, nesta definição, destaca-se a necessidade do estabelecimento de critérios bem definidos, que serão tomados como referência de ideal estabelecido; combinado com a elaboração de parâmetros relevantes e atuais para o contexto onde o referido processo está inserido; além da fundamental necessidade de ação, em relação a um posicionamento ativo, a fim de orientar e corrigir possíveis distorções.

Sendo assim, a avaliação não pode se limitar a um simples instrumento classificatório e seletivo, muitas vezes com fim em si mesma, desconexa da realidade e da situação individual de cada aluno, desatenta às diferenças e às particularidades individuais.

Stumpf e Bergamaschi (2016, p. 930) apontam que "a avaliação ocidental prejudica a aprendizagem, pois se baseia na cobrança, competição e padronização, com a exigência da adequação do aluno a um sistema preestabelecido, sem respeito às diferenças e às formas diversas de compreensão neste processo de aprendizagem."

Nesse sentido, faz-se necessário envidar esforços para se buscar estratégias adequadas de avaliações personalizadas, não comparativas e classificatórias, que atendam às necessidades individuais dos estudantes, respeitando seus ritmos, bem como suas evoluções particulares, além de proporcionar oportunidades de reflexões e melhorias a todo momento, inclusive durante a própria avaliação.

Assim, inserido na avaliação, encontra-se o feedback, que é um retorno dado ou recebido sobre habilidades, conhecimentos, comportamentos e atitudes. O feedback está presente em todas as relações interpessoais. Ele ocorre de maneira formal ou informal, podendo ser verbal e não-verbal e, dependendo da maneira que se oferece, apresentará caráter construtivo ou destrutivo, afetando diretamente o estado de ânimo das pessoas.

Neste trabalho, é utilizada a definição de Luna (2009) sobre feedback, retroalimentação ou realimentação. O feedback é uma atividade que informa sobre as competências das pessoas, sobre o que elas sabem, sobre o que fazem e sobre a maneira como atuam. Permitindo assim descrever o pensar, o sentir e o atuar de uma pessoa em seu ambiente, e, portanto, revelando como é seu desempenho e como pode ele melhorar no futuro.

No contexto escolar, este feedback deveria passar, inicialmente, por uma intervenção individualizada, junto a cada aluno, através do oferecimento de retorno pessoal para que cada aluno possa tomar consciência de sua aprendizagem, bem como de suas necessidades pessoais de complementação e reforço, promovendo uma reflexão sobre a construção do seu próprio conhecimento.

Entretanto, no processo ensino-aprendizagem as atividades de ensino e avaliação são realizadas em momentos não simultâneos, distintos e não imediatos. Geralmente, é trabalhado todo o assunto, para somente em momento posterior, já com acúmulo de assuntos tratados, serem oferecidas oportunidades de avaliações e correções, ou seja, perde-se a oportunidade da 
intervenção imediata, precisa e menos extensa de retomar a assuntos que, eventualmente, não foram bem compreendidos pelos alunos.

Neste contexto, a avaliação é vista como uma etapa final de um processo, fechada em si mesma, que visa o encerramento de um ciclo ou de uma caminhada, a fim de verificar a aprendizagem de um certo objeto do conhecimento.

Há de se destacar que a atividade de feedback aproxima a relação entre professor e aluno, o que permitirá ao professor maior e melhor conhecimento individualizado do aluno. Já para o aluno, maior interação com o professor, possibilitando um atendimento particular de suas necessidades, sendo a aprendizagem facilitada, quando os alunos recebem feedback (COLLINS, 2004).

Mas, mesmo conscientes da importância da utilização de feedback no processo ensinoaprendizagem, cabe ressaltar algumas dificuldades práticas na sua implementação, tais como: pouco tempo de contato presencial entre professores e alunos, grande esforço demandado em atividades de correção, com curto espaço de tempo para executá-las, e a rapidez do feedback.

Diante de tais adversidades, faz-se necessária a utilização de estratégias complementares que auxiliem o professor no oferecimento de um feedback imediato e eficiente para os alunos, uma vez que feedback pode se traduzir em melhores desempenhos dos alunos (FESTAS, 2015).

Nesse cenário de busca de alternativas, segundo Coll e Monereo (2010), o computador pode se adaptar às características do usuário, comparando suas condutas, além de registrar todas as suas intervenções e procedimentos, possibilitando a recuperação de informações de maneira rápida e eficiente. Portanto, a utilização dos recursos das Tecnologias de Informação e Comunicação (TICs), através de ambientes informatizados, poderão desempenhar papel fundamental na elaboração, na execução, na correção e, principalmente, no oferecimento de feedback aos alunos.

E, ainda, as avaliações realizadas com o auxílio das TICs, oferecem resultados que podem ser quantificados e analisados de forma mais prática e objetiva (RODRIGUES, 2015), convergindo com a estratégia de oferecimento de feedback imediato.

Além disso, Melo (2016, p. 457) aponta a influência das tecnologias sobre o cotidiano e a vida escolar:

\begin{abstract}
O período das tecnologias já é o presente: praticamente todos os ramos da atividade humana estão sendo permeados por um grande, e sempre crescente, número de dispositivos, aplicativos e ferramentas relacionadas com as Tecnologias de Informação e Comunicação. $E$, nessa perspectiva, o ensino-aprendizagem também é influenciado e contemplado pelas mais diversificadas formas de ferramentas tecnológicas.
\end{abstract}

Por outro lado, em particular, a disciplina de matemática vem apresentando resultados dramáticos nas avaliações de larga escala como o PISA e a Prova Brasil. Ano após ano, os alunos não conseguem atingir o nível adequado de aprendizagem nessa disciplina, sendo incapazes de aplicar conceitos fundamentais, bem como utilizar com desenvoltura o raciocínio lógico (ARAÚJO; RIBEIRO JÚNIOR, 2017).

Sendo assim, cresce em importância a busca de estratégias pedagógicas que visem diminuir esse fracasso, a fim de promover melhorias no processo de ensino-aprendizagem da matemática.

As dificuldades emergentes da disciplina de matemática se apresentam em decorrência de vários fatores, como por exemplo, a própria linguagem particular da matemática, que muitas vezes gera uma lacuna entre a linguagem usual do dia-a-dia e o que é trabalhado no contexto escolar. Outro fator, que se destaca entre as dificuldades na disciplina, é a falta de pré-requisitos para continuidade dos assuntos, uma vez que a matemática tem caráter bastante sequencial e interligado de desenvolvimento de assuntos (RESENDE; MESQUITA, 2013).

Além disso, muitas vezes, a matemática é abordada de forma descontextualizada da realidade do aluno, sem qualquer aproximação do mundo real, o que pode gerar uma sensação de distanciamento entre a disciplina e suas aplicações para o cotidiano das pessoas.

Sendo assim, a questão de pesquisa é: como oferecer um sistema de feedback imediato e personalizado aos alunos em ambientes informatizados, com o uso das TICs, na disciplina de matemática? 
O presente trabalho tem como objetivo analisar a implementação de um sistema de avaliação que ofereça feedback rápido em ambientes informatizados, na disciplina de matemática, compreendendo a participação e o desempenho dos alunos.

Vale destacar que, num processo avaliação, sendo esta integrante ativa do processo ensinoaprendizagem, é possível e natural que ocorram inseguranças e erros. E, nessas situações, o professor deve utilizá-los didaticamente como situação de aprendizagem, uma vez que os alunos normalmente procuram averiguar por qual motivo eles cometeram certos erros (TORRE, 2007).

Essa necessidade dos alunos, em compreender os seus próprios erros, é uma ótima oportunidade de desenvolver uma capacidade de reflexão e análise. Com isso, tomam consciência de suas dificuldades e falhas e percebem a necessidade da correção, a fim de superar os erros na busca da construção do próprio conhecimento.

Sendo assim, tem-se uma mudança de paradigma, pois é possível tratar o próprio erro processual numa perspectiva diagnóstica. Tal perspectiva é, por si só, fonte de exploração para melhoria da aprendizagem, através de estratégias específicas e individualizadas para cada aluno, pelo oferecimento de feedback imediato, preciso e adequado.

Segundo Torre (2007, p. 89), "Se o erro pode ser aproveitado como elemento concomitante ao processo de aprender, a conscientização do aluno de erros e equívocos pode ser aproveitada para descobrir por que se falhou". É nesta perspectiva que se pretende elaborar atividades em função das falhas detectadas, através de um feedback imediato e preciso, para corrigir e evitar novos erros.. Ou seja, ofertar ao aluno a possibilidade de reconhecer o erro em momento oportuno, superar esse erro, aprender com a própria falha e seguir aprendendo.

\section{Trabalhos Relacionados ao Feedback}

O termo feedback, no contexto da educação, tem sua origem na escola behaviorista, sendo usado para reforçar ou descartar respostas (CARDOSO, 2011). O behaviorismo procurava explicar a relação existente entre condições anteriores, comportamento e condições consequentes, isto é, a relação bidirecional entre estímulo e resposta (LEFRANÇOIS, 2015). Nessa perspectiva, o feedback assume um caráter limitador de reforçar respostas corretas e refutar respostas incorretas, sem a preocupação em compreender a ocorrência do erro, quando ele ocorria.

Entretanto, o feedback passa a assumir outra interpretação a partir das teorias cognitivista, nos anos 70 e 80, momento em que o erro passou a ser valorizado como fonte de compreensão do processo cognitivo do aluno e sua influência no ensino e na aprendizagem (CARDOSO, 2011).

No trabalho realizado por Cardoso (2011), a autora apresenta um estudo teórico sobre a utilização do feedback no contexto escolar, comparando os retornos oferecidos pelos docentes em sala de aula presencial com aqueles ofertados no ensino a distância (EaD). Na escola, o feedback é dotado de interações entre professor e alunos, constituídas de elementos verbais e não-verbais de forma mais próxima e imediata. Já no EaD, os alunos não podem dispor de interações próximas e imediatas com o professor, o que pode causar isolamento e falta de motivação. Dessa forma, nessa modalidade de ensino, o oferecimento de feedback é fundamental, pois pode aproximar alunos e professores, evitando a sensação de isolamento e impessoalidade, além de orientar e motivar esses discentes na realização das atividades.

Cardoso (2011) relata, ainda, que em pesquisa realizada sobre a interação em cursos online, a falta de feedback imediato contribuiu para diminuir a motivação e a participação dos alunos: enquanto os alunos não recebiam o retorno sobre seus questionamentos, eles não postavam novas mensagens.

Vale destacar alguns tipos de feedback apresentados por Cardoso (2011), entre os quais: motivacional/interacional, o qual está relacionado às reações emocionais como resposta à interação; tecnológico, que envolve informações sobre a utilização do software empregado no curso; e o feedback informativo/avaliativo, que fornece informação ou algum tipo de avaliação ao aluno. 
Essas modalidades de retorno são importantes, pois podem ocorrer simultaneamente, num ambiente de aprendizagem mediada por computador, a fim de orientar, esclarecer e motivar a participação do aluno na construção da aprendizagem.

Paiva (2003) discute as interações em ambiente virtual e suas várias formas de manifestação, tanto nas relações homem-máquina como nas interações entre os membros de comunidades virtuais, não se limitando à relação entre professor aluno, mas também considerando a possibilidade de retorno entre pares (aluno e aluno).

A autora apresenta dois tipos de feedback: o avaliativo, que informa sobre o desempenho acadêmico do aluno ou do professor, e o interacional, que registra reações ao comportamento interacional do aluno ou do professor. Apresenta, também, diversas definições, com ênfase ao contexto do feedback virtual, merecendo destaque a definição proposta por Stemler (1997, p. 343), "feedback pode ser definido como output, geralmente visualizado na tela, para informar aos alunos sobre o grau de sucesso na solução de problemas ou para prover informações sobre a qualidade de suas respostas a eventos semelhantes a testes."

Essa definição é importante para o nosso trabalho, uma vez que nossas atividades se desenvolveram em ambientes virtuais de aprendizagem, apoiados com o auxílio da plataforma de ensino Moodle. O feedback proposto neste trabalho é gerado automaticamente na tela do computador, através de respostas imediatas, logo após a realização pelo aluno de cada item do teste.

Medeiros et al. (2010) apresentam os Sistemas de Resposta a Audiência (SRAs), que têm sido utilizados como uma alternativa para obter o contínuo feedback dos alunos em sala de aula, bem como auxiliar o modelo de ensino/aprendizagem no ambiente eletrônico e online. O trabalho apresenta uma análise de diferentes SRAs com ênfase em suas principais funcionalidades. Seu propósito consiste em, a partir das funcionalidades registradas, propor um novo sistema, o EASYSRA, cujo diferencial está no melhoramento deste tipo de sistema através de dispositivos móveis, permitindo a disponibilidade em diferentes idiomas, diferentes possibilidades de votação e integração com redes sociais, além da possibilidade de ser gratuito.

Segundo Medeiros et al (2010), os SRAs são tanto hardwares quanto softwares que permitem estudantes de cursos presenciais ou à distância responderem questões utilizando um aparelho de controle remoto. Após os alunos responderem uma votação, os resultados são apresentados para a classe em um formato visual, usualmente um histograma.

As respostas são coletadas através de dispositivos chamados clicadores, que são pequenos transmissores do tamanho de um controle remoto de televisão onde estudantes respondem questões apertando botões (CALDWELL, 2007).

Os SRA permitem que estudantes respondam a questões anonimamente ou que professores rastreiem através do aparelho de controle remoto para saber de qual estudante veio às respostas. SRA dão feedback contínuo para os estudantes e para o professor sobre o desempenho da classe.

Os SRAs permitem o acompanhamento ágil das respostas dos alunos quando da atividade de avaliação, possibilitando identificar as principais demandas de correção através de feedback imediato e preciso.

Sendo assim, esses sistemas apresentam conhecimento imediato, através da votação dos alunos, a respeito dos seus desempenhos, orientando o professor na condução dos trabalhos, cabendo ao docente propor atividades complementares de feedback. Isto é, faz-se necessária a intervenção do professor na interpretação dos resultados apresentados pelo SRA, para, em seguida, propor atividades de correção. Assim, o SRA apresenta o feedback genérico, que é o mais simples, pois ele apenas indica se aluno está certo ou errado, não oferecendo o retorno situado. O feedback situado busca simular com mais riqueza uma interação face-a-face, pois ele é um comentário a respeito de um segmento da resposta do aluno (LEFFA, 2003).

No trabalho apresentado por Shute (2009), a autora desenvolve pesquisas sobre retroalimentação, em especial sobre o feedback formativo, que é definido como uma informação comunicada ao aluno que se destina a modificar o pensamento ou o comportamento do aluno com a finalidade de melhorar a aprendizagem. 
A autora discute, após ampla pesquisa bibliográfica, algumas variedades de tipos de feedback, por exemplo, verificação da exatidão da resposta, explicação da resposta correta, sugestões e exemplos trabalhados. Essas alternativas podem ser administrados em vários momentos durante o processo de aprendizagem, por exemplo, imediatamente após uma resposta, ou após algum período de tempo decorrido após. A autora também destaca o grande número de pesquisas na área do feedback com resultados diversos, incluindo, alguns conflitantes.

Shute (2009) esclarece que o foco da sua pesquisa é o feedback no nível da tarefa, o qual geralmente fornece informações mais específicas e oportunas (muitas vezes em tempo real) ao aluno sobre uma resposta específica a um problema ou tarefa.

Em seu estudo, a autora apresenta alguns procedimentos que tornam a retroalimentação ineficiente, ou até mesmo prejudiciais à aprendizagem, tais como: feedback crítico ou de controle; fornecimento de notas ou de pontuações globais indicando a posição do aluno em relação aos colegas; e o oferecimento de retornos que interrompem um aluno que está ativamente engajado na resolução de problemas.

Observando os trabalhos acima citados, fica evidente uma literatura bastante ampla e consistente sobre a utilização do feedback no processo ensino-aprendizagem em cursos de EaD, sobretudo no ensino superior.

Entretanto, acredita-se que ainda foi pouco explorado o uso de feedback em atividades presenciais de complemento e reforço escolar, que utilizem ambientes informatizados, em atividades paralelas ao ensino regular de sala de aula, em especial na Educação Básica.

Nesse sentido, é proposto neste trabalho o uso de feedback imediato na Educação Básica como complemento às aulas regulares, buscando um acompanhamento próximo e personalizado para cada aluno. Este retorno imediato pode ser mais preciso devido ao conhecimento prévio do aluno pelo professor no ambiente presencial e a rapidez da interação professor-aluno agilizado pelo sistema de feedback.

Por outro lado, deve-se ter o cuidado em oferecer oportunidades de feedback que sejam compatíveis com as capacidades cognitivas dos alunos, a fim de agregar qualidade ao processo ensino-aprendizagem, sem confundir, desestimular ou dispersar a atenção dos discentes (SANTOS; TAROUCO, 2007).

Desta forma, a prática pedagógica do docente, como elemento importante do processo ensino-aprendizagem, deve ser uma ação planejada, reflexiva e intencional, levando em conta previsões, expectativas e avaliações de resultados (ZABALA, 1998). Enfim, é possível compreender a importância da avaliação ao longo de todo o processo, não se restringindo a um momento específico, único e finalizador.

\section{Metodologia}

As utilizações das TICs na educação possibilitam um diálogo entre os conhecimentos sistemáticos e formais da escola com os conhecimentos práticos do dia-a-dia inseridos na história e na cultura dos alunos. Os ambientes informatizados podem ser interativos, através de simulações e experimentações, que transformam a atuação do aluno de personagem passivo para agente ativo no processo ensino-aprendizagem, além de ser, segundo Braga et al. (2005, p. 200), "...importante aliado dos professores enquanto ferramenta de apoio e não como mera substituta de outros instrumentos didáticos como livros, por exemplo".

Sendo assim, nossa proposta de trabalho foi realizada em ambiente informatizado, utilizando avaliações formativas com a disponibilização de feedback imediato para os alunos, pois segundo Martínez e Llosa (2010, p. 363) "... para o feedback ser útil, ele deve ser rápido e chegar ao aluno logo depois de realizar sua tarefa."

Acredita-se que o feedback imediato, apresentado em ambiente informatizado, durante a realização de uma avaliação, poderá melhorar o desempenho do aluno. Essa apresentação de retorno respeita o ritmo de aprendizagem do aluno em sincronia com a atividade de avaliação. 
Com a utilização desta estratégia de ensino de acompanhamento das atividades de avaliação desenvolvidas pelos alunos, pretende-se promover uma aprendizagem dinâmica. Pois os discentes participarão de forma efetiva e precisa das atividades pedagógicas, uma vez que acompanham o feedback disponibilizado. Além disso, essa retroalimentação oferece ao professor um controle próximo do desempenho dos alunos, o que lhe permitirá apresentar estratégias mais precisas e individualizadas, adaptando-as de acordo com o desempenho.

Nesse contexto, foi realizada uma intervenção pedagógica num colégio público da cidade de Porto Alegre, no $2^{\circ}$ Ano do Ensino Médio (EM), na disciplina de matemática, em 2 turmas de aula, totalizando 45 alunos. Todos esses alunos foram convidados a participar do projeto de pesquisa denominado "Avaliação Escolar - Feedback Imediato".

A disciplina de matemática, no $2^{\circ}$ ano do $\mathrm{EM}$, na escola em questão, possui 4 horas-aulas semanais de 45 minutos em cada aula, ministradas normalmente aos pares de aulas, ou seja, 2 horas-aulas num dia da semana, e mais 2 horas-aulas em outro dia da semana.

O assunto abordado na realização desse estudo está inserido na disciplina de matemática, na sequência didática "Geometria Espacial", mais especificamente no capítulo sobre a "Geometria de Posição".

Inicialmente, foi aplicado um pré-teste sobre o assunto geometria de posição, contendo 10 itens, todos de múltipla escolha, que foram respondidos em sala de aula, com a duração de 35 minutos. Esse pré-teste teve por objetivos:

a) identificar o grau de conhecimento inicial que o aluno possuía sobre o assunto, a fim de direcionar o estudo às necessidades apresentadas;

b) dividir a turma em dois grupos ( $A$ e B) de forma "homogênea" em relação ao desempenho inicial no assunto, a fim de classificar esses grupos em "Grupo de Experimento" e "Grupo de Controle".

Destaca-se que os grupo A e B não estarão vinculados ao número da turma (203 ou 204), mas ao desempenho apresentado no pré-teste. Ou seja, no grupo A participaram o 10, o 30, 0 50 , etc, classificados, em relação ao desempenho no pré-teste; e, no grupo B participaram o 20 , o 40, o $6^{\circ}$ alunos, etc, classificados, também em relação ao desempenho no mesmo teste.

Após a realização do pré-teste e com a distribuição dos alunos nos grupos de acordo o critério acima proposto, a média do grupo A foi de 5,97, enquanto a média do grupo B foi de 5,91. Sendo assim, é considero os grupos homogêneos em relação ao desempenho no pré-teste sobre geometria de posição.

O assunto constante no Plano de Execução Didática "geometria de posição" foi trabalhado em sala de aula no horário regular, de acordo com a documentação curricular prevista no Colégio, nas duas turmas envolvidas no experimento, sem qualquer distinção em relação às turmas ou aos grupos $\mathrm{A}$ e $\mathrm{B}$ de alunos.

Após a apresentação e desenvolvimento do assunto "geometria de posição", foi proposto em ambiente informatizado, na plataforma Moodle do Colégio, a realização de um teste contendo 10 (dez) itens de múltipla escolha, que foi respondido na modalidade de Ensino a Distância (EaD), com data e horário previamente acertados com os alunos.

O teste foi aplicado em ambos os grupos A e B (figura 1), contendo 10 (dez) itens, com valor total de 10,0 (dez) pontos, sendo 1,0 (um) ponto para cada item do teste, em que a própria plataforma Moodle realizou a correção, emitindo a nota para o aluno imediatamente após a realização da avaliação.

Nesse trabalho, todos os itens da avaliação foram constituídos por questões de múltipla escolha, a fim de facilitar a correção das respostas, bem como a geração de estatísticas de controle dos alunos usuários. 
Figura 1 - Acesso aos testes dos grupos A e B

\section{Geometria de Posição - Avaliação Parcial}

Selecione o teste abaixo. Você somente terá acesso a um dos grupos, o qual foi previamente selecionada pelo professor

AP Geometria de Posição (Grupo A)

Não disponivel, a não ser que: Você faz parte de Grupo A

AP Geometria de Posição (Grupo B)

Não disponivel, a não ser que: Você faz parte de Grupo B

Fonte: Construída pelos autores

Para cada um dos 10 itens que constituíram a avaliação foi construído um vídeo-feedback. Vale lembrar que o público da pesquisa é constituído por alunos do $2^{\circ}$ ano do EM, portanto adolescentes que, segundo Vargas et al. (2007), é um público que se identifica muito com esse tipo de mídia, ou seja, os vídeos.

A figura 2 é composta por símbolos: os retângulos com cantos arredondados que representam os símbolos INÍCIO e FIM de trajetórias e as peças de quebra-cabeça, que representam as questões pela letra $Q$ seguido do índice $n$, onde $n$ é o número da questão, além de representarem vídeos pela letra $V$ seguido do índice $n$, onde o $n$ é o número do vídeo. Desta forma, a figura 2 representa os diversos caminhos possíveis que definem uma trajetória sequencial com base nas questões de avaliação, que se inicia com o símbolo INíCIO, passando pelas questões $\left(Q_{n}\right.$, $\mathrm{n}=1, \ldots, 10)$, podendo, alternativamente, em função da resposta "certa" ou errada" do aluno, assistir ao respectivo Vídeo-Feedback $\left(V_{n}, n=1, \ldots, 10\right)$. Neste caso, a figura 2, representa 1024 trajetórias distintas em função das respostas "certa" ou "errada". Ou seja, o aluno poderá seguir para a questão seguinte $\left(Q_{n+1}\right)$, com o fluxo indicado pela seta com "traço cheio", sem a obrigatoriedade de assistir ao vídeo correspondente $\left(V_{n}\right)$, se acertou a questão $\left(Q_{n}\right)$. Mas, se a questão $Q_{n}$ for respondida de forma errada, o discente deverá acessar ao vídeo explicativo $\left(V_{n}\right)$ da referida questão conforme o fluxo indicado pela seta com "traço tracejado", para em seguida seguir compulsoriamente para a próxima questão $\left(Q_{n+1}\right)$, com fluxo também indicado pela seta com "traço cheio". Enfim, após a última questão ser respondida, ou o último vídeo ser acessado, o aluno segue o fluxo indicado pela seta com "traço cheio" para o símbolo FIM (retângulo com cantos arredondados com a palavra FIM que indica o final da trajetória) onde será finalizada a avaliação e informada a nota ao aluno.

Figura 2 - Trajeto das questões e seus respectivos vídeos-feedback

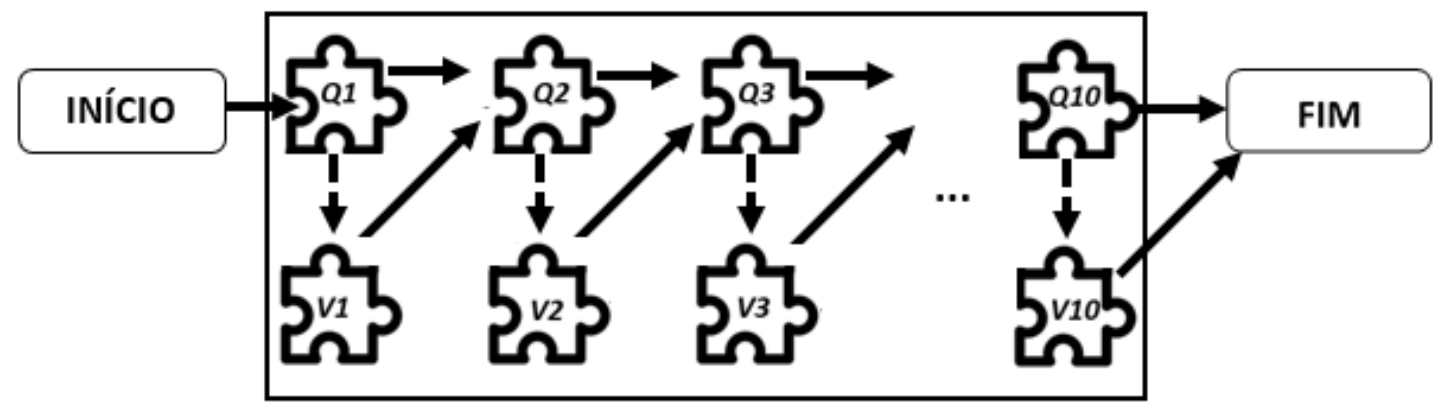

Fonte: Construída pelos autores

Cada um desses vídeos-feedback foi elaborado com a utilização do software Geogebra $\subsetneq$, que possui uma janela de edição em 3D, que permite fácil manipulação, possibilitando mudanças no ângulo de visão das figuras geométricas. Após a preparação do objeto de aprendizagem com a 
utilização do Geogebra (C, foi gravado o vídeo-feedbck, com a utilização de software de gravação da tela do computador, no qual a solução detalhada era apresentada. Esse vídeo foi compartilhado no site "www.youtube.com.br", com a inserção de link na plataforma Moodle do Colégio, a fim de ser acessado logo em seguida após cada questão.

Para o grupo A de alunos (Grupo de Experimento), o teste realizado apresentou, após cada um dos 10 itens da avaliação, o vídeo-feedback com a solução imediata e detalhada do item, logo que o aluno enviava a sua resposta para cada item do teste. Ao aluno que acertava um certo item, o vídeo-feedback tinha o caráter opcional de consulta; e, ao aluno que errava o item, o vídeo-feedback (figura 3) apresentava-se com o caráter obrigatório de acesso.

Figura 3 - Interface de acesso ao vídeo-feedback

A sua resposta está incorreta. Você deverá acessar ao vídeo-feedback abaixo.

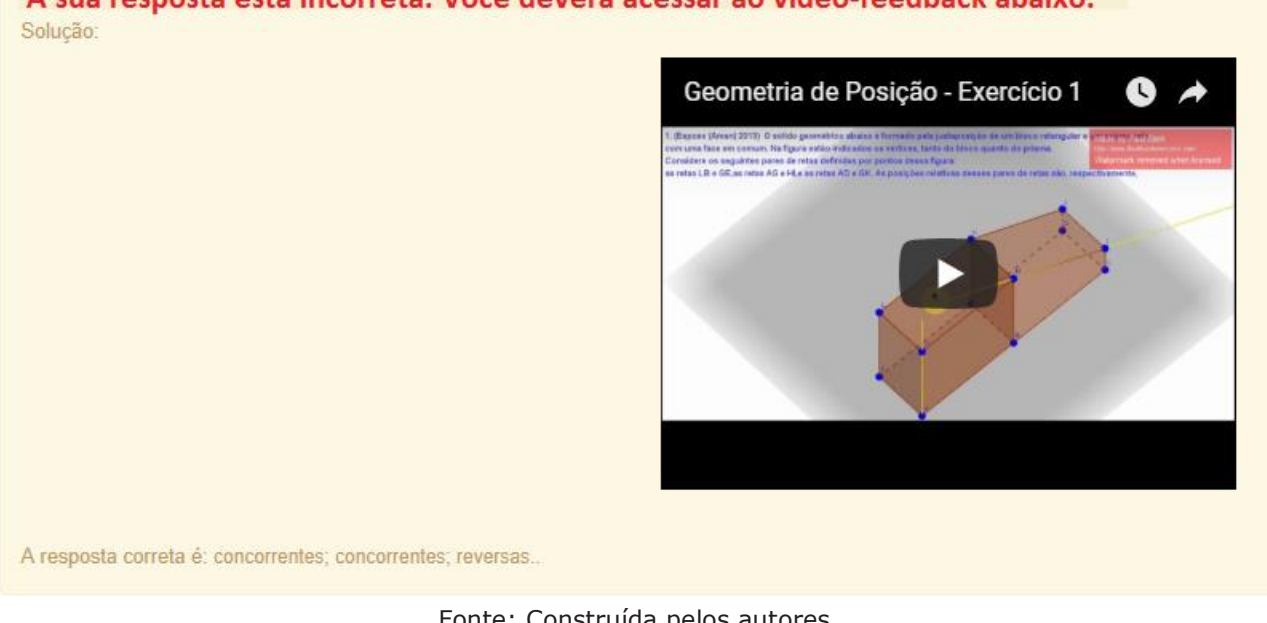

Fonte: Construída pelos autores

Já para o grupo B (Grupo de Controle), foi realizado o mesmo teste do grupo A, entretanto não foi apresentado nenhum feedback imediatamente após o envio da resposta sugerida pelo aluno.

Para aplicação do projeto foi utilizada a ferramenta "Questionário" da plataforma Moodle. Essa ferramenta permitiu a elaboração de diversos itens de avaliação, que podem ser utilizados também, além do computador, em dispositivos móveis como celulares e tablets.

Assim, os 45 alunos participantes do experimento pedagógico "Avaliação Escolar - Feedback Imediato" realizaram a avaliação sobre o assunto geometria de posição, em ambiente EaD, obrigando aos alunos do Grupo A a assistirem aos vídeos-feedback correspondentes às questões erradas. Para aqueles que acertaram as questões é opcional o acesso ao vídeos-feedback correspondentes. Quanto aos alunos do Grupo B estes não receberam nenhum tipo de feedback, nem imediato nem posteriormente.

\section{Resultados Encontrados}

Após a realização da avaliação sobre o assunto "geometria de posição" em ambiente informatizado EaD, na plataforma Moodle, os resultados estatísticos dos grupos A e B são apresentados abaixo (tabela 1 ):

Tabela 1 - Estatística do teste sobre "geometria de posição"

\begin{tabular}{|c|c|c|}
\cline { 2 - 3 } \multicolumn{1}{c|}{} & Grupo A & Grupo B \\
\hline Tamanhos das Amostras & $n_{1}=23$ & $n_{2}=22$ \\
\hline Dédias das amostras & $x_{1}^{\prime}=7,56$ & $x_{2}^{\prime}=6,36$ \\
\hline
\end{tabular}

Fonte: Construída pelos autores 
A partir desses resultados foram realizadas análises estatísticas para verificar a hipótese de que o oferecimento de feedback imediato, apresentado em ambiente informatizado, logo em seguida a realização de uma avaliação, através de plataforma de EaD, poderia promover o desempenho dos alunos.

A fim de verificar o desempenho comparativo entre os grupos A (Grupo de Experimento) e Grupo B (Grupo de controle) foi levado em consideração a medida estatística de centralidade "média aritmética".

Inicialmente, fez-se necessário a realização do "teste $F^{\prime \prime}$ para determinar se as variâncias populacionais com amostra dupla eram iguais (LARSON; FABER, 2010), conforme valores apresentados na tabela 1 . Esse estudo prévio foi realizado para verificar a adequabilidade do teste $t$, que seria aplicado em seguida.

Em nosso experimento, o "teste $\mathrm{F}^{\prime}$ apontou que não há diferença significativa quanto às variâncias das duas amostras.

Portanto, a partir do "teste F" realizado, foi considerado as duas variâncias iguais, sendo, em seguida, possível aplicar o "teste $\mathrm{t}^{\prime \prime}$ para verificar a diferença entre as médias das notas dos grupos A e B de alunos.

Segundo Larson e Faber (2010), um "teste t de Student"ou simplesmente "teste t" de duas amostras é usado para testar a diferença entre duas médias populacionais $\mu_{1} \mathrm{e} \mu_{2}$ quando uma amostra é selecionada aleatoriamente de cada população, com tamanho de amostra menor que 30, cujas amostras são independentes e selecionadas aleatoriamente.

Ainda, de acordo com Larson e Faber (2010), a distribuição amostral para a diferença entre as médias da amostra $x_{1}-x_{2}$ pode ser aproximada por uma distribuição t com média $\mu_{1}-\mu_{2}$.Sendo assim, foi possível em nosso trabalho usar um "teste $\mathrm{t}^{\prime \prime}$ para verificar a diferença entre duas médias populacionais $\mu_{1}$ e $\mu_{2}$.

Neste estudo, foi admitido que as populações são distribuídas normalmente e utilizado o teste de hipótese com as seguintes condições:

A afirmação é:a média das notas dos alunos do grupo A é maior que a média das notas dos alunos do grupo B.

Hipóteses:

Ho: $\mu_{1} \leq \mu_{2}$

$\mathrm{H} 1: \mu_{1}>\mu_{2}$ (afirmação)

Nessa pesquisa, de acordo com o "teste F" aplicado, as variâncias são consideradas iguais e, portanto, segue na aplicação do "teste $t^{\prime}$ que o grau de liberdade g.l. é ado por g.l. = n1 + n2 2. Ou seja, g.l. $=22+23-2=43$. Como g.l. = $43>29$, adota-se g.l. "infinito", conforme indicado numa tabela $t$.

Já que o teste é unicaudal à direita, com $\mathrm{g}, \mathrm{l} .=43$ ea $=0,10$, consultando a tabela de estatística $t$, tem-se como valor crítico $t_{0}=1,282$.

Para as informações acima (tabela 1), considerando o nível de significância igual a a $=0,10$, tem-se que a estatística de teste padronizado resultou o valor de $t \approx 1,465$.

Vale esclarecer que, segundo Larson e Faber (2010), a estatística de teste padronizado t é dado por:

O erro padrão $\sigma_{\dot{x}_{1}-x_{2}^{\prime}}$ é dado por:

$$
t=\frac{\left(x_{1}^{\prime}-x_{2}^{\prime}\right)-\left(\mu_{1}-\mu_{2}\right)}{\sigma_{x_{1}^{\prime}-x_{2}^{\prime}}}
$$

$$
\sigma_{\dot{x}_{1}-\chi_{2}^{\prime}}=\sqrt{\frac{\left(n_{1}-1\right) S_{1}^{2}+\left(n_{2}-1\right) S_{2}^{2}}{n_{1}+n_{2}-2}}
$$

O gráfico abaixo (figura 4) apresenta a estatística de "teste $t^{\prime \prime}$, no qual estão representados o valor crítico $t_{0}=1,282$, bem como o valor resultado da estatística $t \approx 1,465$. 
Figura 4 - Estatística de teste t para a comparação das médias dos grupos A e B

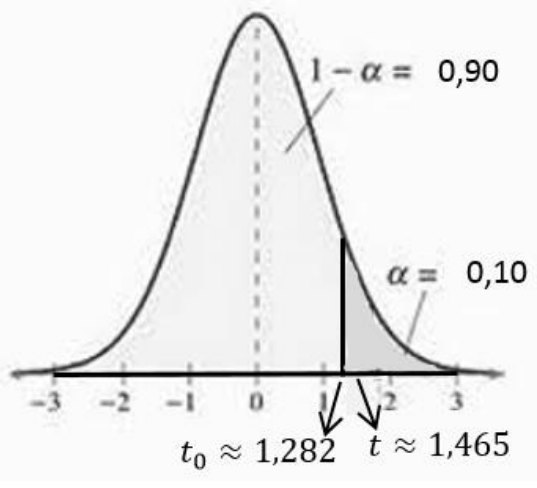

Fonte: Construída pelos autores

De acordo com o gráfico da estatística de "teste $t$ " (figura 3), como t $\approx 1,465$ está localizado na região de rejeição da hipótese nula, concluímos que, no nível de significância de $10 \%$, há evidências suficientes para apoiar a afirmação de que a média das notas dos alunos do grupo $A$ foi maior do que a média das notas dos alunos do grupo $B$.

Ou seja, de acordo com o "teste t" apresentado, utilizado para comparar a média das notas dos grupos A e B na avaliação sobre o assunto "geometria de posição" em ambiente informatizado EaD, na plataforma Moodle, o desempenho dos alunos do grupo de experimento, com média 7,56 , foi melhor do que o desempenho dos alunos do grupo de controle, que obteve média 6,36.

\section{Considerações Finais}

A principal contribuição deste trabalho é agilizar o retorno através de oferta imediata de um vídeo explicativo sobre a solução da questão respondida incorretamente pelo aluno (vídeofeedback). Com isto o aluno se sente mais amparado nos seus erros quando realiza atividades a distância, reduzindo a probabilidade de esquecimento do contexto no qual ocorreu a dificuldade.

O vídeo-feedback planejado previamente segundo objetivos bem definidos fará parte integrante da trajetória de aprendizagem antecipando o tratamento e a apresentação dos elementos relacionados a falta de base ou subsunçores prévios dos alunos proporcionando assim a oportunidade de conscientização dos motivos de seus erros.

Acredita-se que quanto mais cedo este feedback aconteça mais cedo o aluno terá suas dúvidas sanadas evitando que se acumulem lacunas que venham a comprometer os próximos assuntos a serem abordados.

Destaque-se aqui que, com o objetivo de evitar sobrecarga cognitiva, os vídeos-feedback devem ser ater à questão trabalhada e com a duração máxima de 180 segundos.

Embora o acesso ao vídeo-feedback seja obrigatório em caso de erro das questões, os recursos tecnológicos implementados permitem que, mesmo em caso de acerto, opcionalmente, os alunos podem assisti-lo.

Nesse sentido, o presente trabalho fez um experimento pedagógico aplicando o sistema implementado, que oferece retorno imediato através de vídeos-feedback relativos às questões de avaliação da disciplina de matemática sobre o assunto "geometria de posição" na modalidade EaD, por meio da plataforma Moodle. Esta estratégia tem como vantagem principal evitar a proliferação de vídeos-feedback, pois para cada questão se implementou somente um vídeo.

Este experimento pedagógico realizado comparou as médias dos grupos de experimento e de controle (teste t) mostrando evidências suficientes que indicam a promoção do desempenho dos alunos na disciplina de matemática quando existe retorno imediato. Assim, foi possível apresentar uma resposta viável para a questão inicial desse trabalho, ou seja, "Como oferecer 
um sistema de feedback imediato e genérico aos alunos com o uso das TICs na disciplina de matemática?".

Outra sugestão de trabalhos futuros é a realização de novos experimentos semelhantes a este, com a utilização de outros assuntos em matemática, com a utilização de uma amostra maior de participantes, a fim de reforçar os indícios apresentados neste estudo.

Vale destacar, ainda, que a avaliação realizada sobre o assunto "geometria de posição" em ambiente informatizado EaD, consistiu de testes de múltipla escolha, com cinco alternativas para cada uma das questões.

Numa avaliação do tipo teste com múltiplas escolhas, além da resposta correta, cada uma das outras opções de resposta contempla distratores diferentes, que possuem necessidades e dificuldades particulares, as quais precisam de tratamento e acompanhamento individualizados, a fim de responder com oportunidade a cada uma das alternativas de cada questão de uma avaliação.

Nossa proposta de vídeo-feedback não contemplava individualmente cada uma das alternativas de cada questão do teste realizado pelos alunos, mas apresentava um retorno geral para cada uma das questões, independente da alternativa assinalada pelo discente.

Sendo assim, faz-se necessário, como trabalho futuro, a implementação de um processo de vídeos-feedback, que apresente a resposta apropriada para cada alternativa assinalada de cada questão de uma avaliação, a fim de contemplar de maneira precisa a cada distrator presente numa alternativa incorreta.

\section{Informações dos autores}

MSc Jorge Nazareno Batista Melo

Programa de Pós-Graduação em Informática na Educação - Universidade Federal do Rio Grande do Sul - UFRGS, Brasil, jorge_cmpa@yahoo.com.br

\section{Dr. Alberto Bastos do Canto Filho}

Programa de Pós-Graduação em Informática na Educação - Universidade Federal do Rio Grande do Sul - UFRGS, Brasil, jorge_cmpa@yahoo.com.br

\section{Dr. José Valdeni de Lima}

Programa de Pós-Graduação em Informática na Educação - Universidade Federal do Rio Grande do Sul - UFRGS, Brasil, jorge_cmpa@yahoo.com.br

\section{Agradecimentos}

Colégio Militar de Porto Alegre (CMPA) e Programa de Pós-Graduação em Informática na Educação (PPGIE) da Universidade Federal do Rio Grande do Sul (UFRGS). CAPES e CNPq pelo apoio financeiro ao Programa.

\section{Referências Bibliográficas}

ARAÚjO, J. P. A. P.; RIBEIRO JúNIOR, J. G. Plataforma Matematech: um Recurso Didático no Ensino de Matemática nos Anos Iniciais do Ensino Fundamental. Revista Informática na Educação: teoria \& prática. Porto Alegre, v.20, n.2, mai./ago. 2017. Disponível em: <http://seer.ufrgs.br/index.php/InfEducTeoriaPratica/article/view/63769/43618>. Acesso em: 12 nov 2017.

BRAGA, D. V.; MARRONI, F. V.; FRANCO, P. P. Tecnologia e(m) Sala de Aula: oportunidades para (re)conciliar a internet e o trabalho do professor. Revista Informática na Educação: teoria \& prática. Porto Alegre, v. 18, n. 2, jul./dez. $2015 . \quad$ Disponível em: <http://seer.ufrgs.br/index.php/InfEducTeoriaPratica/article/view/57230/36455>. Acesso em: 10 nov. 2017. 
CARDOSO, A. C. S. Feedback em contextos de ensino-aprendizagem on-line. Linguagens e Diálogos, v. 2 , n. 2, p. 17-34, 2011.

COLLINS, J. C. Education Techniques for Lifelong Learning: Principles of Adult Learning. Radiographics. 2004; 24:1483-1489.

FESTAS, M. I. F. A aprendizagem contextualizada: análise dos seus fundamentos e práticas pedagógicas. Revista Educação e Pesquisa, São Paulo, v. 41, n. 3, p. 713-728, jul./set. 2015.

LEFFA, V. J. Análise Automática da resposta do aluno em ambiente virtual. Revista Brasileira de Linguística Aplicada. Belo Horizonte: v.3, n.2, 2003.

LARSON, R.; FARBER, B. Estatística Aplicada. 4a Edição. São Paulo: Editora Pearson Prentice Hall, 2010.

LEFRANÇOIS, G. R. Teorias de aprendizagem. São Paulo: Cengage Learning, 2015.

LUCKESI, C. C. Avaliação da aprendizagem escolar: estudos e proposições. 19.ed. São Paulo: Cortez, 2008.

LUNA, P. Á. LA IMPORTANCIA DE LA RETROALIMENTACIÓN EN LOS PROCESOS DE EVALUACIÓN. Una revisión del estado del arte. Querétaro, México, 2009.

MARTÍNEZ, C. A.; LLOSA, J. F. E. Evaluación formativa con feedback rápido usando mandos interactivos. A: JENUI 2010. "XVI Jornadas de Enseñanza Universitaria de la Informática". Santiago de Compostela: Universidade de Santiago de Compostela. Escola Técnica Superior d'Enxeñaría, p. 363-370, 2010.

MEDEIROS, A.F.C.; SOUZA, T. H. J. O.; BEZERRA, E. P.; SILVA, J. C. EASY-SRA: Um sistema de resposta à audiência para avaliação contínua. Revista Novas Tecnologias na Educação, CINTED/UFRGS, v. 10, no 3, 2012.

MELO, J. N. B. A utilização de ambientes informatizados através da plataforma Moodle com atividades complementares e de reforço para as aulas regulares de sala de aula. Revista Eletrônica de Educação Matemática (REVEMAT), UFSC, v. 11, n. 2, 2016. Disponível em: < https://periodicos.ufsc.br/index.php/revemat/article/view/1981-1322.2016v11n2p457/33651>. Acesso em: 19 out. 2017.

PAIVA, V. L. M. O. Feedback em ambiente virtual. In: LEFFA.V. (Org.). Interação na aprendizagem das línguas. Pelotas: EDUCAT, p.219-254, 2003.

RESENDE, G.; MESQUITA, M. G. B. F. Principais dificuldades percebidas no processo ensino-aprendizagem de Matemática em escolas do município de Divinópolis (MG). Educação Matemática Pesquisa: Revista do Programa de Estudos Pós-Graduados em Educação Matemática, v. 15, n. 1, 2013.

RODRIGUES, E. F. A avaliação e a tecnologia. A questão da verificação de aprendizagem no ensino híbrido. In: Ensino Híbrido: Personalização e tecnologia da educação. BACICH, L.; NETO, A. T.; TREVISANI, F. M. (org.). Porto Alegre: Penso, 2015.

SANTOS, L. M. A.; TAROUCO, L. M. R. A importância do estudo da teoria da carga cognitiva em uma educação tecnológica. Novas Tecnologias na Educação. CINTED, v.5, n.1, 2007.

STEMLER, L. K. educational characteristics of multimedia: a literature review. Journal of Educational Multimedia and Hypermedia. Charlottesville: Association for the Advancement of Computing in Education (AACE), v. 6, n.3/4, p.339-359, 1997.

STUMPF, B. O.; BERGAMASCHI, M. A. Elementos espirituais, simbólicos e afetivos na construção da escola mbyá guarani. Revista Educação e Pesquisa, São Paulo, v. 42, n. 4, p. 921-935, out./dez. 2016. Disponível em: <http://www.educacaoepesquisa.fe.usp.br/wp-content/uploads/2016/04/Livro-v42v4.pdf>. Acesso em: 19 out. 2017 
SUNAGA, A.; CARVALHO, C. S. As Tecnologias Digitais no Ensino Híbrido. In: BACICH, Lilian; NETO, Adolfo Tanzi; TREVISANI, Fernando de Mello (org.). Ensino Híbrido: personalização e tecnologia na educação. Porto Alegre: Penso, 2015.

TORRE, S. L. Aprender com os erros: o erro como estratégia de mudança. Artmed: Porto alegre, 2007.

VARGAS, A.; ROCHA, H. V.; FREIRE, F. M. P. Promídia: produção de vídeos digitais no contexto educacional. Novas Tecnologias na Educação - UFRGS/CINTED. v. 5, n. 2, dez. 2007. Disponível em: http://www.cinted.ufrgs.br/ciclo10/artigos/1bAriel.pdf Acessado em: 31/05/2017.

ZABALA, A. A prática Educativa: como ensinar. Artmed: Porto Alegre, 1998.

Recebido em novembro de 2017

Aprovado para publicação em julho de 2018

Jorge Nazareno Batista Melo

Colégio Militar de Porto Alegre, jorge_cmpa@yahoo.com.br

\section{José Valdeni de Lima}

Universidade Federal do Rio Grande do Sul, valdeni@inf.ufrgs.br

\section{Alberto Bastos Canto Filho}

Universidade Federal do Rio Grande do Sul, alberto.canto@ufrgs.br 